\title{
Knowledge Assessment Supported by Interval Numbers and Concept Lattices
}

\author{
Knowledge assessment
}

\author{
Sylvia Encheva* \\ Stord/Haugesund University College \\ Bjørnsonsg. 45, 5528, Haugesund, Norway \\ Polytec, Sørhauggata 128, 5527 Haugesund, Norway \\ Corresponding author
}

\begin{abstract}
Selection of an optimal knowledge assessment method appears to be a multiple criteria decision making problem among many other things. There is hardly any doubt that working with humans knowledge is always done in the presence of uncertainties. It is also not a secret that a large number of experts in the field of knowledge assessment feel much more comfortable expressing their opinions and statements in linguistic terms and number intervals rather than with crisp values. In this work we address the problem of ranking alternatives for students' knowledge assessment. Interval number theory seems to be an appropriate approach to begin with, when considering the nature of such investigations. While the method is definitely useful for handling interval data it certainly does not indicate what two or more alternatives have in common. This type of information is often required when in real life situations the best theoretically proven alternative cannot be taken. Therefore we propose application of formal concept analyses on the same data in addition to the work performed with interval number theory. Combining these two methods can facilitate multiple attribute decision making processes where for some reasons outcomes of alternatives' rankings with interval numbers have to be reconsidered.
\end{abstract}

Keywords-knowledge assessment; interval numbers; alternatives

\section{INTRODUCTION}

A knowledge-based, highly technological economy requires that students' master higher-order thinking skills and that they are able to see relationships among seemingly diverse concepts, [10]. Both formative and summative assessments [5] of students' knowledge and skills are used by today's educators.

Formative assessment are meant to support learning by supplying current feedback and assist lectures in spotting individual problems like f. ex. misunderstanding, misinterpretation and/or misconception. Summative assessments are used for evaluating amount of knowledge obtained in a predefined time interval.

Introducing new ways to gauge learners' knowledge and abilities is often viewed from different sides. Students going through a variety of evaluation approaches are better equipped to handle future changes in the way their skills and knowledge are assessed. At the same time students who for various reasons experience some difficulties in completing their studies have to spend additional efforts to comply with all kinds of formal requirements. As a result their learning is weakened to a degree that some of them may even drop out.

Selection of an optimal knowledge assessment method appears to be a multiple criteria decision making problem [1] among other things. There is hardly any doubt that operating with humans knowledge is always done in the presence of uncertainties. It is also not a secret that experts in the field of knowledge assessment feel much more comfortable expressing their opinions and statements in linguistic terms and number intervals rather than with crisp values.

In this work we first apply interval numbers for ranking alternatives for knowledge assessments by a method presented in [12]. While the method is definitely useful for handling interval data it does not show what two or more alternatives have in common. To answer such questions we propose application of formal concept analyses [4] on the same data. The combination of the two methods can facilitate a multiple attribute decision process where interval numbers ranking of alternatives has to be reconsidered. More often than not in real life situations the best theoretically proven alternative cannot be taken and another option has to be considered.

\section{BACKGROUND}

Interval arithmetic was introduced in [3] and presented as a formal system in [8] and [9]. A good overview of latest developments in the field is presented in [7].

An interval number is defined in [12] as $a=\left[a^{-}, a^{+}\right]=\{x \mid$ $\left.\mathrm{a}^{-} \leq \mathrm{x} \leq \mathrm{a}^{+}, \mathrm{a}^{-} \leq \mathrm{a}^{+}, \mathrm{a}^{-},\right\}$and $\mathrm{a}^{-}, \mathrm{a}^{+}$are real numbers. If $\mathrm{a}^{+}=0$, the interval reverts to a point, and thus we would return to the basic crisp model. For an excellent selection of definitions and statements related to interval numbers see [12].

Consider a multiple attribute decision making problem with $m$ alternatives and $n$ criteria (in [12] they are referred to as indexes). A decision matrix with interval numbers as elements is defined as $\left[\mathrm{a}_{\mathrm{ij}}{ }^{-}, \mathrm{a}_{\mathrm{ij}}{ }^{+}\right], \quad i=1,2, \ldots, m, \quad j=1,2, \ldots$, $n$. The weight value $w_{j}$ of each criterion is uncertain, but limited. The connection coefficient is denoted by $\xi_{i}(k)$. After calculating $\xi_{i}(k)$, the connection between $i^{t h}$ alternative and reference number sequence will be calculated. The feasible 
alternative $X_{t}$ is optimal by grey related analysis if $r_{t}=\max _{1 \leq i \leq m}{ }^{r}$.

A multiple attribute decision making method applying grey relational analysis is presented in [6].

Let $P$ be a non-empty ordered set. If $\sup \{x, y\}$ and $\inf \{x, y\}$ exist for all $x, y \quad P$, then $P$ is called a lattice, [4]. In a lattice illustrating partial ordering of knowledge values, the logical conjunction is identified with the meet operation and the logical disjunction with the join operation. A context is a triple $(G, M, I)$ where $G$ and $M$ are sets and $I \subset G \times M$. The elements of $G$ and $M$ are called objects and attributes respectively [2], [4], [11]. A concept of the context $(G, M, I)$ is defined to be a pair $(A, B)$ where $A \subseteq G, B \subseteq M, A^{\prime}=B$ and $B^{\prime}=A$. The extent of the concept $(A, B)$ is $A$ while its intent is $B$. A subset $A$ of $G$ is the extent of some concept if and only if $A^{\prime \prime}=A$ in which case the unique concept of the which $A$ is an extent is $\left(A, A^{\prime}\right)$.

\section{RANKING}

Here we apply interval numbers for facilitating a multi-criteria decision making process related to evaluation of students' knowledge and skills. Most of the calculations are done following [12]. A lecturer is considering both summative and formative assessments:

A1 - a final exam only,

A2 - a midterm exam followed by an exam at the end of a course,

A3 - graded compulsory assignments and an exam at the end of a course,

A4 - obligatory participation in tutorials with presentation of problem solutions and an exam at the end of a course,

A5 - portfolio and an exam at the end of a course.

Some authors use the term 'portfolio' to distinguish a case with a final exam only from all other arrangements. In this study by 'portfolio' we mean cases where more than two elements are used in forming the final grade.

Criteria involved in this multi-criteria decision making process are:

$\mathrm{C} 1$ - amount of needed resources

$\mathrm{C} 2$ - incorporation of continues evaluation

C3 - use of technology in the evaluation process

C4 - compatibility with department's policy

C5 - provide opportunities for instructional adjustments during the current study

C6 - degree of promoting independent learning.

Evaluation outcomes of alternatives A1, A2, A3, A4, A5 with respect to the six criteria $\mathrm{C} 1, \mathrm{C} 2, \mathrm{C} 3, \mathrm{C} 4, \mathrm{C} 5, \mathrm{C} 6$ are listed in TABLE I. In this case it is assumed that a greater criterion value is better. The weight for criteria can take values within the following intervals

$$
\begin{array}{lllc}
w_{1} & {[0.0,0.15],} & w_{2} & {[0.1,0.25],} \\
w 3 & {[0.15,0.30], w_{4}} & {[0.2,0.35],} \\
w_{5} & {[0.1,0.15],} & w_{6} & {[0.05,0.2] .}
\end{array}
$$

TABLE I. ALTERNATIVES FOR KNOWLEDGE AND SKILLS EVALUATION

\begin{tabular}{|l||l|l|l|l|l|l|}
\hline & C1 & C2 & C3 & C4 & C5 & C6 \\
\hline \hline A1 & {$[8.5,9.1]$} & {$[0.1,0.5]$} & {$[2.3,2.9]$} & {$[4.3,5.6]$} & {$[1.7,3.6]$} & {$[8.4,9.3]$} \\
\hline A2 & {$[7.4,8.2]$} & {$[0.4,0.9]$} & {$[3.7,5.6]$} & {$[2.9,3.7]$} & {$[2.1,4.3]$} & {$[6.4,7.2]$} \\
\hline A3 & {$[5.1,6.3]$} & {$[3.5,5.8]$} & {$[2.9,7.2]$} & {$[6.6,8.3]$} & {$[4.5,6.9]$} & {$[2.4,3.6]$} \\
\hline A4 & {$[4.6,5.4]$} & {$[4.5,6.2]$} & {$[4.2,5.1]$} & {$[5.1,7.9]$} & {$[7.2,8.9]$} & {$[1.1,2.5]$} \\
\hline A5 & {$[0.3,0.7]$} & {$[8.8,9.2]$} & {$[7.4,8.5]$} & {$[9.1,9.8]$} & {$[8.1,9.3]$} & {$[0.1,0.3]$} \\
\hline
\end{tabular}

The norms of the column vectors defined in TABLE I. are

$\left\|\mathrm{V}_{1}\right\|=9.1,\left\|\mathrm{~V}_{2}\right\|=9.2,\left\|\mathrm{~V}_{3}\right\|=8.5,\left\|\mathrm{~V}_{4}\right\|=9.8,\left\|\mathrm{~V}_{5}\right\|=9.3$ and the resolving coefficient $\rho=0.4$. Note that the smaller $\rho$, the greater its resolving power is.

The rank order for the five alternatives according to their $r_{\mathrm{i}}$ values $r_{1}=0.7652, \mathrm{r}_{2}=0.6309, \mathrm{r}_{3}=0.7497, \mathrm{r}_{4}=0.8246, \mathrm{r}_{5}=$ 0.8103, is $\mathrm{A} 4>\mathrm{A} 5>\mathrm{A} 1>\mathrm{A} 3>\mathrm{A} 2$.

TABLE II. DATA OBTAINED FROM TABLE 1 AFTER INTERVAL CONVERSION

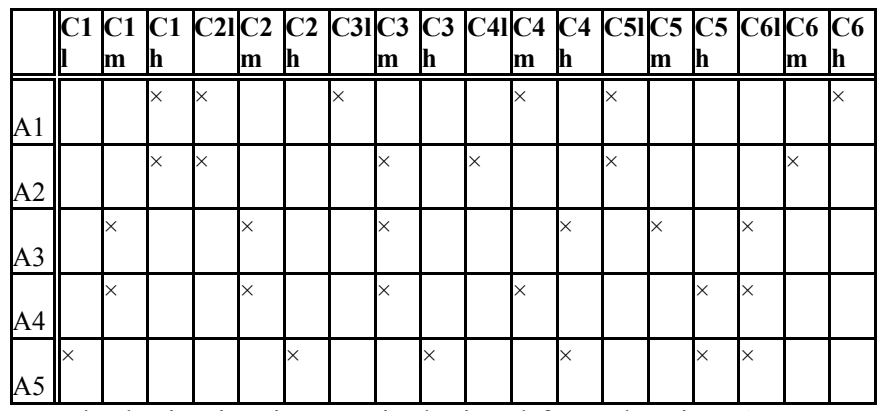

The lattice in Figure I. is depicted from data in TABLE II. applying the following interval conversion: [0.0, 3.9] is denoted as low (1), $[4.0,6.9]$ is denoted as middle (m), and $[7.0,10.0]$ as high $(h)$.

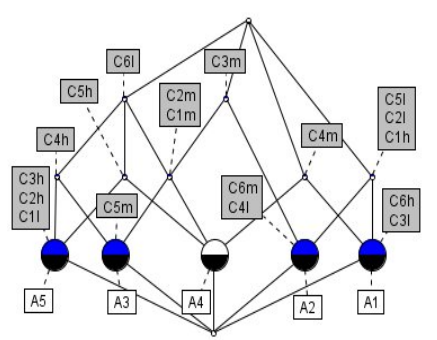

FIGURE I. A LATTICE RELATING ALTERNATIVES AND CRITERIA 


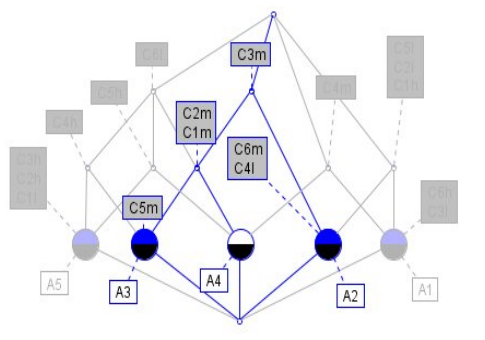

FIGURE II. ATTRIBUTES SHARED BY ATTRIBUTES A2, A3 AND A4

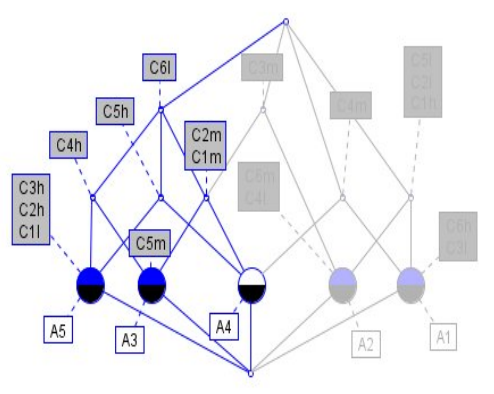

FIGURE III. ATTRIBUTES SHARED BY ATTRIBUTES A3, A4 AND A5

Alternatives A4 and A5 have close $r_{i}$ values but the lattices in fig. 1shows that they have only one attribute in common, i.e. 'Degree of promoting independent learning'. The other two alternatives with close $r_{i}$ values are A1 and A3. They however do not share any common attribute. Another quite interesting observation is related to alternatives A1 and A2. Their $r_{i}$ values are not as close as the ones for the other two couples of attributes but they share three attributes in Figure I. amount of needed resources, incorporation of continues evaluation, and provide opportunities for instructional adjustments during the current study. Thus alternatives A1 and A2 can be considered as a substitution for one another.

In case some of the listed attributes became decision attributes (while the others remain conditional) it is possible to use the already depicted lattice in order to find out which alternatives possess those decision attributes. A lattice illustrating attributes shared by alternatives A2, A3 and A4 is shown in Figure II. It is easy to notice that alternatives A2, A4 and A4 share one attribute only, i.e. $\mathrm{C} 3 \mathrm{~m}$, and no other alternative possess that attribute. On the other hand alternatives A3 and A4 share two attributes, i.e. $\mathrm{C} 1 \mathrm{~m}$ and $\mathrm{C} 2 \mathrm{~m}$.

A lattice illustrating attributes shared by alternatives A3, A4 and A5 is shown in Figure III. It is easy to notice that alternatives A3, A4 and A5 share one attribute only, i.e. C61, and no other alternative possess that attribute. On the other hand alternatives $\mathrm{A} 3$ and $\mathrm{A} 4$ share two attributes, i.e. $\mathrm{C} 1 \mathrm{~m}$ and $\mathrm{C} 2 \mathrm{~m}$, while alternatives A3 and A5 share one attribute only, i.e. C4h, and alternatives A4 and A5 share also only one attribute, i.e. $\mathrm{C} 5 \mathrm{~h}$.

Nodes and vertices in Figure II. and Figure III. emphasizing the described dependencies are highlighted.

Once faculty members are done with their assessment choices they should synchronize subjects' requirements at least on semester base in order to avoid over-testing students.

\section{CONCLUSION}

Interval numbers appear to be quite useful when it comes to handling uncertain data in a systematic way. In addition they allow choice of precision level by selection of resolving coefficient values. In case the ranking outcome, after applying the interval numbers method, has to be reconsidered we recommend using formal concept analysis. The latter provides information about which criteria are shared by the involved alternatives. This can be used in a decision making process when the first option in an obtained ranking cannot be taken in practice.

\section{REFERENCES}

[1] C-T. Chang, K-H.Tan, and H-C. Lu, "Multiple Criteria Decision Making Theory, Methods, and Applications in Engineering", Mathematical Problems in Engineering, 2014.

[2] B. A. Davey and H. A. Priestley, "Introduction to lattices and order", Cambridge University Press, Cambridge, 2005.

[3] P. S. Dwyer, "Linear Computation", Wiley, New York, NY, USA, 1951.

[4] B. Ganter and R. Wille, "Formal Concept Analysis", Springer, 1999.

[5] C. Garrison and M. Ehringhaus, Formative and Summative Assessments in the Classroom, http://schoolpress.cshgreenwich.org/cshmstechclass/2014/02/05/formativ e-summative-assessments-classroom-2/

[6] Y. Kuoa, T. Yangb and G-W. Huangb, "The use of grey relational analysis in solving multiple attribute decision-making problems", Computers and Industrial Engineering, vol. 55, no. 1, pp. 80-93, 2008.

[7] S. A. Mohiuddine, K. Raj and A. Alotaibi, "On Some Classes of Double Difference Sequences of Interval Numbers", Abstract and Applied Analysis, pp. 1-8, 2014.

[8] R. E. Moore, "Automatic Error Analysis in Digital Computation", LSMD-48421, Lockheed Missiles and Space Company, 1959.

[9] R. E. Moore and C. T. Yang, "Interval analysis I", Tech. Rep. LMSD-285875, Lockheed Missiles and Space Company, 1962.

[10] E. Staff, "How Should We Measure Student Learning? The Many Forms of http://www.edutopia.org/comprehensive-assessment-introduction

[11] R. Wille, "Concept lattices and conceptual knowledge systems", Computers Math. Applications, vol. 23, no. 6-9, pp. 493-515, 1992.

[12] J. Zhang, D. Wu and D. L. Olson, "The method of grey related analysis to multiple attribute decision making problems with interval numbers", Mathematical and Computer Modelling, vol. 42, no. 9-10, pp. 991-998, 2005 . 